\title{
Maxillary sinus septa: prevalence, morphology, diagnostics and implantological implications. Systematic review
}

\author{
M. Malec, T. Smektała, G. Trybek, K. Sporniak-Tutak \\ Department of Dental Surgery, Pomeranian Medical University, Szczecin, Poland \\ [Received 29 October 2013; Accepted 2 December 2013]
}

\begin{abstract}
Background: The purpose of this review is to indicate the prevalence of septa, illustrate the most adequate diagnostic method and further discuss pre-operative considerations and implantological implications.

Materials and methods: On June 30 th, 2013 , a comprehensive database search was executed using PubMed (Medline) and Google Scholar. No time frames were applied. Only publications in English, Polish and German in peer-reviewed journals were considered.

Results: The final number of articles was 55: 7 articles were found to describe the possible aetiology of sinus septa, 34 articles describing the prevalence, 21 including information on classification, 19 showed methods of diagnosis and 24 articles included practical information about the influence of the septa in pre- and implantation surgery. One article could be found in more than one category.

Conclusions: Septa can be found in 9\% to $70 \%$ patients (mean prevalence: about $36 \%$ ) in every age group - young dentate patients as primary septa and old edentate or edentulous patients as primary or secondary septa more frequent in edentate or edentulous patients. When planning any surgical procedures, septa incidence should be taken into consideration. Precise information about the septa can be obtained from computed tomography (CT) or cone-beam CT. With development of the knowledge and surgical technique, septa appearance has simply become another option for treatment as any form of disadvantage. (Folia Morphol 2014; 73, 3: 259-266)
\end{abstract}

Key words: dental implants, sinus floor augmentation, maxillary sinus

\section{INTRODUCTION}

Sinus septa were first described in literature in 1909 by Underwood [47]. They are bony walls rising from the sinus floor and divide the cavity into compartments. Septa, if missed, may cause unexpected difficulties during surgery. With the increasingly importance of peri-implant surgery, the understanding of the presence of septa has vastly increased. They have become an obstacle and may significantly hinder sinus augmentation procedures. To overcome this problem, common surgical methods had to be modified. The purpose of this review is to indicate the prevalence of septa, illustrate the most adequate diagnostic method and further discuss pre-operative considerations and implantological implications. 
Table 1. Inclusion and exclusion criteria for eligibility assessment process

\begin{tabular}{ll}
\hline Inclusion criteria & Exclusion criteria \\
\hline Human studies & Animal studies \\
Literature from 1909 & \\
Articles in Polish, English, German language & Articles in other languages \\
Notes about maxillary sinus septa & Notes about nasal septa and intra-alveolar septa \\
$\begin{array}{l}\text { Anatomy, physiology, difference in anatomical structures } \\
\text { including septa }\end{array}$ & $\begin{array}{l}\text { Diseases, congenital and acquired malformations, tumours } \\
\text { of maxillary sinuses }\end{array}$ \\
$\begin{array}{l}\text { Diagnostic of maxillary sinus septa (panoramic radiographs, computed } \\
\text { tomography; cone-beam computed tomography, transillumination, } \\
\text { intraoperative and cadaver study) }\end{array}$ & \\
Surgery and implantology of maxillary sinuses concerned with septa & Peri-implant surgery without septa significance \\
\hline
\end{tabular}

\section{MATERIALS AND METHODS}

On June $30^{\text {th }}, 2013$, a comprehensive database search was executed using PubMed (Medline) and Google Scholar. No time frames were applied. Only publications in English, Polish and German in peer-reviewed journals were considered. A single search equation was used for the search process: ("Maxillary Sinus" [Mesh] OR maxillary sinus OR Sinus maxillaris OR sinus Highmori OR sinus Highmore) AND (septa OR septum).

The titles and abstracts obtained were screened and evaluated by 2 observers according to inclusion and exclusion criteria (Table 1). Studies not meeting the inclusion criteria were excluded from further evaluation. Finally, article bibliographies that passed the eligibility assessment were screened, with any discrepancies in the selection settled through discussion. Prisma flow diagrams presented the search and evaluation process (Fig 1).

\section{RESULTS}

416 articles were initially found. After verification in terms of inclusion/exclusion criteria, 365 articles were excluded. Additional searching using the same search equation performed in Google Scholar resulted in 1 new article. The final number of articles was 50 from a database search plus 4 coming from bibliographies screening.

All selected articles were divided into 5 categories: aetiology, prevalence, classification, diagnosis and significance in pre- and implantation surgery. This division was created to clarify and optimise the presentation of results. Seven articles were found to describe the possible aetiology of sinus septa, 34 articles describing the prevalence, 21 including information on classification, 19 showed methods of diagnosis and 24 articles included practical information about the influence of the septa in

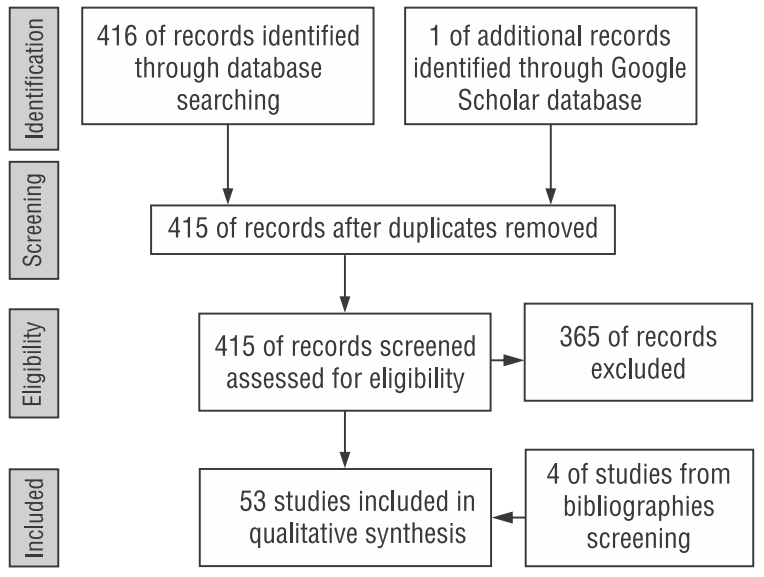

Figure 1. Prisma flow diagram presenting literature search and evaluation process.

pre- and implantation surgery. One article could be found in more than one category.

\section{DISCUSSION}

\section{Aetiology}

Our search revealed a number of hypotheses that were described in literature. Underwood suggested that bony septa are thin, shattered and sharp ended and are related to tooth development. They arise from the floor between the area of 2 adjacent teeth and divide the sinus into 3 compartments: anterior, middle and posterior [47, 48]. Naitoh et al. [32] suggested that septa may be a kind of reinforcement to hold the volume and shape of maxillary sinus and could be an effect of disharmony during the growth of bone surface sutures in the alveolar process and maxillary sinus. Van den Bergh et al. [49] stated that septa are carrying masticatory forces during the dentate phase 
of life and after tooth loss they disappear. Neivert [33] proposed the idea that septa were derived from the "fingerlike projections" produced during embryological out-pouching of the ethmoid infundibulum in cases when the clinging wall did not resorb. Vinter et al. [52] stated that they are an effect of the irregularly process of sinus floor atrophy in different regions creating "bony crests", calling them secondary septa. Ulm et al. [46], was close to Vinter's hypothesis, and suggested biomechanically septa remains were the border of 2 post pneumatisation regression zones, allowing for the transfer of masticatory pressure.

Among the many presented hypothesis Krennmair's dichotomous division seems the most likely: 1) primary septa, formed during the development of bony head structures and the head's height, increase with the growing process of the head; 2) secondary septa are formed after tooth loss in the process of maxillary alveolar atrophy.

\section{Classification}

Krennmair et al. [21], as previously mentioned, divided septa into primary and secondary. Primary are connected with the development of head structures. They are higher than the secondary and may occur in dentate or edentulous patients. Secondary septa are an effect of alveolar process pneumatisation. In most cases they are lower and occur only in edentulous maxillas $[6,51,52]$. Results have shown a greater number
Table 2. Maxillary sinus septa prevalence depends on patients' dentition

\begin{tabular}{lccc}
\hline Authors & Dentate & $\begin{array}{c}\text { Partially } \\
\text { dentate }\end{array}$ & Edentulous \\
\hline Krennmair et al. [21] & $13.2 \%$ & & $26.8 \%$ \\
Lee et al. [26] & $19.3 \%$ & & $27.7 \%$ \\
Koymen et al. [20] & & $39.2 \%$ & $46.4 \%$ \\
Van Zyl and & $66 \%$ & & $71 \%$ \\
van Heerden [50] & & & \\
Velásquez-Plata et al. [51] & & $66.7 \%$ & $33 \%$ \\
Park et al. [37] & $38.7 \%$ & $37.8 \%$ & $23.4 \%$ \\
Orhan et al. [36] & $3.8 \%$ & $37.8 \%$ & $3.4 \%$ \\
\hline
\end{tabular}

of septa in partially edentulous and edentulous than in dentate patients $[20,21,26,36,50,51]$. Park et al. [37] reported dissimilar results, finding more septa in dentate maxillas (Table 2).

Major studies present the occurrence of mostly 1 septum $[13,17,19,20,26,31,32,34,37,41,43$, 44, 46, 51], except van Zyl and van Heerden [50] who found 2 septa. The highest number of septa was $4[20,37,43,50,51]$. Septa may be complete or partial; complete septa divide the maxillary sinus into separate compartments. However more commonly, they are partial (Table 3).

As Underwood [48] stated, the maxillary sinus can be divided into three compartments: anterior

Table 3. Number of maxillary septa occurring in 1 patient

\begin{tabular}{|c|c|c|c|c|c|c|}
\hline \multirow[t]{2}{*}{ Authors } & \multicolumn{2}{|c|}{ Number of examined } & \multirow[t]{2}{*}{1} & \multirow[t]{2}{*}{2} & \multirow[t]{2}{*}{3} & \multirow[t]{2}{*}{$>3$} \\
\hline & Subjects & Sinuses & & & & \\
\hline Neugebauer et al. [34] & 1029 & & 253 & 30 & 20 & \\
\hline Naitoh et al. [31] & 15 & & 10 & 1 & & \\
\hline Koymen et al. [20] & 205 & 410 & 69 & 28 & 8 & 4 \\
\hline Ulm et al. [46] & & 41 & 11 & 2 & & \\
\hline Van Zyl and van Heerden [50] & 200 & & 49 & 51 & 27 & 11 \\
\hline Velásquez-Plata et al. [51] & 156 & 312 & 64 & 4 & 1 & 4 \\
\hline Shen et al. [43] & 423 & 846 & 65 & 49 & 9 & 1 \\
\hline Gosau et al. [13] & 65 & & 14 & 9 & 1 & \\
\hline Lee et al. [26] & & 204 & 50 & 8 & & \\
\hline Park et al. [37] & 74 & & 47 & 19 & 6 & 2 \\
\hline Kasabah et al. [17] & & 68 & 22 & 2 & & \\
\hline Rysz and Bakoń [41] & & 222 & 40 & 8 & 1 & \\
\hline Shibli et al. [44] & 1024 & & 135 & 86 & 1 & \\
\hline Kim et al. [19] & 100 & 200 & 48 & 4 & 1 & \\
\hline
\end{tabular}


Table 4. Average height of septa across the studies

\begin{tabular}{lc}
\hline Authors & Average height of septa [mm] \\
\hline Neugebauer et al. [34] & Transversely: $7.3 \pm 5$ \\
Sagittally: $11.7 \pm 6$ \\
Naitoh et al. [31] & 3.8 \\
Ulm et al. [46] & 7.9 \\
Van Zyl and van Heerden [50] & $6.2 \pm 3.7$ \\
Krennmair et al. [21] & $8.1 \pm 2.5$ \\
Velásquez-Plata et al. [51] & Laterally: $3.5 \pm 3$ \\
Gosau et al. [13] & Medially: $5.9 \pm 3$ \\
Maestre-Ferrin et al. [29] & 5.4 \\
Orhan et al. [36] & 4.9 \\
Rosano et al. [39] & Males: $4.86 \pm 2,01$ \\
\hline
\end{tabular}

(between premolars), middle (between first molar and second molar) and posterior (above the third molar). Some authors have made small changes but generally this classification is still accepted [48]. Krennmair et al. [21] differs in 2 areas: the middle - first molar and posterior - second molar, Velásquez-Plata et al. [51], Kim et al. [19] and Lee et al. [26] - 3: anterior- second premolar, the middle - between the second premolar and second molar, posterior - behind second molar.

The septa can be oriented sagittally, transversally, horizontally or atypically. Naitoh et al. [32] marked the position of the septa in relation to the transverse palatal suture; Park et al. [37] found buccopalatal, sagittal and transversal type of septa. Sagittally and transversely orientated septa were found by Neugebauer et al. [34], Krennmair et al. [21], Underwood [48]. Van Zyl and Heerden [50], Shen et al. [43], Koymen et al. [20], Kasabah et al. [17], Ulm et al. [46], Orhan et al. [36] divided septa orientation into: buccopalatal/ /mediolateral orientated, Rosano et al. [39] — anteriorlateral, sagittal and transversal, finally Selcuk et al. [42] proposed vertical and horizontal position.

The height of the septa varies from up to $11.7 \mathrm{~mm}$, anything lower than $2 \mathrm{~mm}$ was treated by most authors as exostoses. Van Zyl and Heerden [50], Naitoh et al. [32], Kim et al. [19] did not excluded septa at any height [51]; Lee et al. [26] classified septa as bony walls with a height of more than $2.5 \mathrm{~mm}$, Naitoh et al. [31] over $2 \mathrm{~mm}$ and Rosano et al. [39] over $3 \mathrm{~mm}$ (Table 4).

The angles of septa orientation were also measured by: 1) Park et al. [37] (the angle between sagittal section and septa) with a mean of $76.29^{\circ}$ on the right side and a mean of $83.94^{\circ}$ on the left, 2) Naitoh et al. [31] from $40.6^{\circ}$ to $86.8^{\circ}, 3$ ) Orhan et al. [36] $34.1^{\circ}$ to $123.6^{\circ}$ depending on the sinus region $[31,32,36,37]$.

\section{Prevalence}

Prevalence ranges from $9.5 \%$ to $69 \%$ and widely differs depending on the diagnostic method. Across studies, septa were examined with panoramic radiograph (OPG) $[12,17,18,22,32,44]$, computed tomography (CT) $[12,14,15,17-22,26-28,31$, $32,37,41-43,46,50,51]$, cone-beam computed tomography $(\mathrm{CBCT})[15,23,34,36,38]$, in vitro cadaver studies $[9,13,22,31,32,39,41,46,54]$ and intraoperative examination $[45,55]$. The highest incidence was found by Maestre-Ferrín [28] - 70\% (CT) and van Zyl and van Heerden [50] - 69\% (CT), the lowest by Yang et al. [54] - 9\% in cadaver studies (Table 5). Some authors examined the difference between gender/sex $[19,20,26,36,37,43,50]$. The incidence was higher in males, excluding Park et al. [37] who found more septa in females (Table 6). Our review also revealed that the septum was more often on left side than on right $[19,26,36,37,43,51]$ but the difference was relatively small. Only Koymen et al. [20] found more septa on right side (Table 7).

The highest prevalence was in the middle and anterior region. Lee et al. [26] and Gonzales-Santana et al. [12] stated that the greatest number was found in the middle region and Ulm et al. [46] in the anterior region (Table 8 ).

\section{Diagnostics}

During diagnostic process of sinus septa, a number of different methods were applied: OPG, CT, $\mathrm{CBCT}$, direct examination, percussion, endoscopy, palpation and transillumination (Table 5) [2, 3, 37]. In OPG, septa cannot be decisively excluded or detected because they cannot be clearly differentiated from other anatomic structures $[9,46]$. Some authors found that OPG gives a false diagnosis in the range of $11.8-52.68 \%$ [17, 20, 21, 28, 38, 49] compared to $\mathrm{CT}$. CT caused a kind of revolution in the radiological diagnostic of hard tissue. It is very helpful in the accurate diagnosis of maxilla structures and for the planning of surgical procedures. CT also allows a practitioner to determine the thickness of the Schneiderian membrane $[4,26,28,37]$. With highly advanced diagnostic methods and an image-guided procedure, septa can be viewed in detail $[5,10,40]$. In the use of 3 dimensional (3D) images some errors 
Table 5. Numerical and percentage rate of the maxillary sinus septa occurrence across the literature

\begin{tabular}{|c|c|c|c|c|c|}
\hline \multirow[t]{2}{*}{ Authors } & \multirow[t]{2}{*}{ Diagnostic method } & \multicolumn{2}{|c|}{ Number of examined subjects } & \multicolumn{2}{|c|}{ Number of subjects with septa } \\
\hline & & Sinuses & Persons & Persons & Sinuses \\
\hline Kasabah et al. [17] & $\mathrm{OPG} / \mathrm{CT}$ & 68 & 34 & & $24(35.9 \%)$ \\
\hline Gonzales-Santana et al. [12] & $\mathrm{OPG} / \mathrm{CT}$ & 60 & 30 & $7(25 \%)$ & \\
\hline Shibli et al. [44] & OPG & & 1024 & $221(21.6 \%)$ & \\
\hline Lee et al. [26] & CT & 236 & 204 & $55(27 \%)$ & $58(24.6 \%)$ \\
\hline Ulm et al. [21] & Cadaver & & 41 & & $13(31.7 \%)$ \\
\hline \multirow[t]{5}{*}{ Krennmair et al. [21, 22] } & OPG/CT & 265 & 165 & & $32(16 \%)$ \\
\hline & & 194 & & & \\
\hline & & 61 & & $17(27.8 \%)$ & \\
\hline & & 41 & & $13(31.7 \%)$ & \\
\hline & & 42 & & $12(28.5 \%)$ & \\
\hline Underwood [48] & Cadaver & 90 & 45 & & $30(33 \%)$ \\
\hline Velásquez-Plata et al. [51] & CT & 312 & 156 & $51(32.7 \%)$ & $75(24 \%)$ \\
\hline Rysz and Bakoń [41] & CT & 222 & & & $49(26 \%)$ \\
\hline Neugebauer et al. [34] & СВСТ & 2058 & 1029 & $484(47 \%)$ & $683(33.2 \%)$ \\
\hline \multirow[t]{2}{*}{ Naitoh et al. [31, 32] } & СВСТ & 30 & 15 & $7(47 \%)$ & $11(37 \%)$ \\
\hline & Cadaver & 88 & 44 & & $(41.7 \%)$ \\
\hline Koymen et al. [20] & CT & 410 & 205 & & $145(35.4 \%)$ \\
\hline Van Zyl and van Heerden [50] & CT & 400 & 200 & $138(69 \%)$ & $222(56 \%)$ \\
\hline Shen et al. [43] & $\mathrm{CT}$ & 846 & 423 & $124(29.3 \%)$ & $173(20,45 \%)$ \\
\hline Kfir et al. [18] & OPG/CT & & 57 & $26(45.6 \%)$ & \\
\hline Gosau et al. [13] & Cadaver & 130 & 65 & $24(27 \%)$ & \\
\hline \multirow[t]{2}{*}{ Maestre-Ferrín et al. [28] } & OPG/CT & 60 & & & $32(53.3 \%)$ \\
\hline & & & & & $42(70 \%)$ \\
\hline Park et al. [37] & CT & 400 & 200 & $74(37 \%)$ & $111(27.7 \%)$ \\
\hline Ella et al. [9] & Cadaver & 150 & & $29(39 \%)$ & \\
\hline Kim et al. [19] & CT & 200 & 100 & $38(38 \%)$ & $53(26.5 \%)$ \\
\hline Lugmayr et al. [27] & CT & 200 & 100 & & $26(13 \%)$ \\
\hline Nunes et al. [35] & СВСТ & 252 & & & $67(26.59 \%)$ \\
\hline Lana et al. [23] & СВCT & & 500 & $222(44 \%)$ & \\
\hline Güncü et al. [14] & CT & 242 & & & $39(16.1 \%)$ \\
\hline Orhan et al. [36] & СВCT & 544 & 272 & & $316(58 \%)$ \\
\hline Kang et al. [15] & СT & & 150 & & $(44 \%)$ \\
\hline Rosano et al. [39] & Cadaver & 60 & 30 & $12(40 \%)$ & $20(33.3 \%)$ \\
\hline Toscano et al. [45] & Intra-op & & 50 & & $(30 \%)$ \\
\hline Yang et al. [54] & Cadaver & & 74 & $7(9.5 \%)$ & \\
\hline Zijderveld et al. [55] & Intra-op & & 100 & $(48 \%)$ & \\
\hline Selcuk et al. [42] & СТ & 330 & & & $151(22.8 \%)$ \\
\hline
\end{tabular}

Cadaver — cadaver study; CBCT — cone-beam computed tomography; CT — computed tomography; Intra-op — intraoperative sinus examination; OPG — panoramic radiograph

may occur, due to differences that take place during the transformation from 2D slices to a 3D reconstruction. Though reconstructions present a smaller number of artefacts but are less accurate [36, 37]. CBCT can show results as precisely as in vitro/in vivo examinations [34].

\section{Significance in pre- and implantation surgery}

Sinus septa may cause some disadvantages in surgical treatment and may show relative contraindication for sinus lifting. Some authors have stated that there is a negative correlation between the septum and the thickness of the Schneiderian membrane 
Table 6. Occurrence according to gender

\begin{tabular}{lcc}
\hline Authors & Male & Female \\
\hline Park et al. [37] & $35 \%$ & $39 \%$ \\
Lee et al. [26] & $30 \%$ & $23 \%$ \\
Van Zyl and van Heerden [50] & $44 \%$ & $27 \%$ \\
Shen et al. [43] & $34.8 \%$ & $24.1 \%$ \\
Koymen et al. [20] & $55.2 \%$ & $48.7 \%$ \\
Kim et al. [19] & $32.3 \%$ & $18.3 \%$ \\
Orhan et al. [36] & $50 \%$ & $44.8 \%$ \\
\hline
\end{tabular}

Table 7. Septa prevalence according to patient side

\begin{tabular}{lccc}
\hline Author & Left side & Right side & Both sides \\
\hline Park et al. [37] & $36.5 \%$ & $32.4 \%$ & $31.1 \%$ \\
Lee et al. [26] & $25.4 \%$ & $23.6 \%$ & \\
Shen et al. [43] & $20.6 \%$ & $20.3 \%$ & \\
Koymen et al. [20] & $44.7 \%$ & $55.3 \%$ & $29.1 \%$ \\
Kim et al. [19] & $52.5 \%$ & $47.5 \%$ & \\
Velasquez-Plata et al. [51] & $52 \%$ & $48 \%$ & \\
Orhan et al. [36] & $55 \%$ & $44.9 \%$ & $59.8 \%$ \\
\hline
\end{tabular}

that is tightly attached to the septa and may lead to the membrane tearing especially in situations where the septa are sharp edged [4-7, 30, 37, 55]. Alternatively, Ella et al. [9] and Kasabah et al. [16] have stated that there is no connection between the membrane tearing and the presence of the septa, where sinus lift takes place subperiosteally and the elevation of the mucosa is possible without tearing. Another problem during the sinus augmentation procedure is the preparation of an opening window, which is challenging due to the thicker bony walls. Inserting graft material may also cause complications [1, 37]. Therefore the height of the septa may have an influence on augmentation [34]. The difficulty in dividing Septa can be put into 3 categories: (E) easy, (M) moderate and (D) difficult based on location, height and number [53]. When the septa are lower than $2 \mathrm{~mm}$ or situated in a position which will not disturb the procedure, other treatments are not required. However a medium sized, high, sagittally or horizontally and multiple situated Septa can limit access to the maxillary sinus and required more advanced procedures by modifying the shape of the opening window [24, 49] in the following methods:

- "W" shaped access [6, 49];

- double or triple the window size and then remove the septa $[6,24,45,49]$;

- outline the window [55];

- prepare a trap door only on medial sinus lob (mesially to septa) or scalloped trap door [8];

- outfracture a trap door end re-adaption [25];

- inverted hinge door to create an area for grafting material [21];

- 2 trapezoidal bony windows on the other side of the septum, infracture the bony window and remove sharp edge [2].

Table 8. Number and percentage of maxillary sinus septa depends on alveolar process region

\begin{tabular}{lccc}
\hline Author & Anterior region & Middle region & Posterior region \\
\hline Gonzales-Santana et al. [12] & 6 & 7 & 2 \\
Naitoh et al. [31] & 7 & 5 & 25 \\
Koymen et al. [20] & 30 & 110 & $1(6.6 \%)$ \\
Ulm et al. [46] & $11(73.3 \%)$ & $3(19.9 \%)$ & $24 \%$ \\
Van Zyl and van Heerden [50] & $26 \%$ & $49 \%$ & $14(23.7 \%)$ \\
Kim et al. [19] & $15(24.5 \%)$ & $30(50.8 \%)$ & $26(35 \%)$ \\
Velásquez-Plata et al. [51] & $18(24 \%)$ & $31(41 \%)$ & $28.6 \%$ \\
Gosau et al. [13] & $42.9 \%$ & $28.6 \%$ & $15(22.7 \%)$ \\
Lee et al. [26] & $18(27 \%)$ & $33(50 \%)$ & $22.5 \%$ \\
Maestre-Ferrín et al. [28] & $17.5 \%$ & $60 \%$ & $35(31.5 \%)$ \\
Park et al. [37] & $25(22.5 \%)$ & $51(45.9 \%)$ & $53(27.32 \%)$ \\
Shen et al. [43] & $31(15.98 \%)$ & $105(54.12 \%)$ & 225 \\
Neugebauer et al. [34] & 139 & 257 & $70(18.6 \%)$ \\
Orhan et al. [36] & $45(12.2 \%)$ & $254(69.1 \%)$ & $17(2.5 \%)$ \\
Selcuk et al. [42] & $134(20.3 \%)$ & & \\
\hline
\end{tabular}


Due to complications connected with the traditional sinus lift procedure some other augmentation methods can be used to prevent this trauma:1) minimally invasive antral membrane balloon [18];

- supplementary or simultaneous LeFort osteotomy [21];

- horseshoe osteotomy [21];

- nasal floor elevation [21];

- antrostomy [8].

Completely different was Fortin's [11] technique in case of septa occur; the technique was based on placing the implant directly into the septa without any augmentation procedure.

\section{CONCLUSIONS}

1. The prevalence of maxillary sinus septa ranges from $9 \%$ to $70 \%$, with a mean of $36 \%$.

2. Septa can be found in every age group - young dentate patients as primary septa and old edentate or edentulous patients as primary or secondary septa with a greater amount in edentate or edentulous.

3. The most common case is one septum on the left side.

4. When planning any surgical procedures, septa incidence should be taken into consideration. Precise information about the septa can be obtained from $\mathrm{CT}$ or $\mathrm{CBCT}$.

5. With development of the knowledge and surgical technique, septa appearance has simply become another option for treatment as any form of disadvantage.

\section{REFERENCES}

1. Beretta $M$, Cicciù $M$, Bramanti $E$, Maiorana C (2012) Schneider membrane elevation in presence of sinus septa: anatomic features and surgical management. Int J Dent [online] [access: 03 July 2013].

2. Betts NJ, Miloro M (1994) Modification of the sinus lift procedure for septa in the maxillary antrum. J Oral Maxillofac Surg, 52: 332-333.

3. Borris TJ, Weber CR(1998) Intraoperative nasal transillumination for maxillary sinus augmentation procedures: a technical note. Int J Oral Maxillofac Implants, 13: 569-570.

4. Cakur B, Sümbüllü MA, Durna D (2013) Relationship among schneiderian membrane, underwood's septa, ant the maxillary sinus inferior border. Clin Implantol Dent Relat Res [online], 15: 83-87 [access 12 February 2013]. Available on: http://onlinelibrary.wiley.com; doi/10.1111/ j.1708-8208.2011.00336.x/full>.

5. Chan HL, Wang HL (2011) Sinus pathology and anatomy in relation to complications in lateral window sinus augmentation. Implant Dent, 20: 406-412.

6. Chanavaz M (1990) Maxillary sinus: anatomy, physiology, surgery, and bone grafting related to implan- tologyeleven years of surgical experience (1979-1990). J Oral Implantol, 16: 199-209.

7. Cho SC, Wallece SS, Froum SJ, Tarnow DP (2001) Influence of anatomy of Schneiderian membrane perforations during sinus elevation surgery: three-dimensional analysis. Pract Proced Aesthet Dent [online], 13: 160-163.

8. Chris M, Buggenkate T, van den Bergh JPA (1998) Maxillary sinus floor elevation: a valuable pre-prosthetic procedure. Periodontol 2000, 17: 176-182.

9. Ella B, Da Costa Noble R, Lauverjat Y, Séderat C, Zwetyenga $N$, Siberchicot F, Caix P (2008) Septa within the Sinus: effect on elevation of the sinus floor. Br J Maxillofac Surg, 46: 464-467.

10. Fortin T, Camby E, Alik M, Isidori M, Bouchet H (2013) Panoramic images versus three-dimensional planning software for oral implant planning in atrophied posterior maxillary: a clinical radiological study. Clin Implant Dent Relat Res, 15: 198-204.

11. Fortin T, Isidori M, Bouchet H (2009) Placement of posterior maxillary implants in partially edentulous patients with severe bone deficiency using CAD/CAM guidance to avoid sinus grafting: a clinical report of procedure. Int J Oral Maxillofac Implants, 24: 96-102.

12. Gonzales-Santana H, Penarrocha-Diago M, Guarinos-Carbo J, Sorni-Bröker M (2007) A study of the septa in maxillary sinuses and the subantral alveolar process in 30 patients. J Oral Implantol, 33: 340-343.

13. Gosau M, Rink D, Driemel O, Draenert FG (2009) Maxillary sinus anatomy: a cadaveric study with clinical implications. Anat Rec, 292: 352-354.

14. Güncü GN, Yildirim YD, Wang HL, Tözüm TF (2011) Location of posterior superior alveolar artery and evaluation of maxillary sinus anatomy with computerized tomography: a clinical study. Clin Oral Implants Res, 22: 1164-1167.

15. Kang SJ, Shin SI, Herr Y, Kwon YH, Kim GT, Chung JH (2013) Anatomical structures in the maxillary sinus related to lateral sinus elevation: a cone beam computed tomographic analysis. Clin Oral Implants Res, 24: 75-81.

16. Kasabah S, Krug J, Šimůnek A, Lecaro MC (2003) Can we predict maxillary sinus mucosa perforation? Acta Med, 46: 19-23.

17. Kasabah S, Slezák R, Simùnek A, Krug J, Lecaro MC (2002) Evaluation of the accuracy of panoramic radiograph in the definition of maxillary sinus septa. Acta Medica, 45: 173-175.

18. Kfir E, Goldstein M, Ravaelov R, Yerushalmi I, Kfir V, Mazor Z, Kaluski E (2009) Minimally invasive antral membrane balloon elevation in the presence of antral septa: a report of 26 procedures. J Oral Implantol, 35: 257-268.

19. Kim MJ, Jung UW, Kim CS, Kim KD, Choi SH, Kim CK, Cho KS (2006) Maxillary sinus septa: prevalence, heigh,location and morphology. A reformatted computed tomography scan analysis. J Periodontol,77: 903-908.

20. Koymen R, Gocmen-Mas N, Karacayli U, Ortakoglu K, Ozen T, Yazici AC (2009) Anatomic evaluation of maxillary sinus septa: surgery and radiology. Clin Anat, 22: 563-570.

21. Krennmair G, Ulm CW, Lugmayr H (1997) Maxillary sinus septa: incicence, morphology and clinical implications. J Craniomaxillofac Surg, 25: 261-265.21.

22. Krannmair G, Ulm CW, Lugmayr H, Solar P (1999) The incidence, location, and height of maxillary sinus septa in the edentulous and dentate maxilla. J Oral Maxillofac Surg, 57: 667-671.

23. Lana JP, Carneiro PM, Machado VdeC, de Souza PE, Manzi FR, Horta MC (2012) Anatomic variations and lesions of the maxillary sinus detected in cone beam computed tomography for dental implants. Clin Oral Implants Res, 23: 1398-1403.

24. Lee HW, Lin WS, Morton D (2013) A retrospective study of complications associated with 100 consecutive maxillary 
sinus augumentations via the lateral window approach. Int J Oral Maxillofac Implants, 28: 860-868.

25. Lee JK (2012) Outfracture osteotomy on lateral maxillary wall as a modified sinus graft technique. J Oral Maxillofac Surg, 68: 1639-1641.

26. Lee WJ, Lee SJ, Kim HS (2010) Analysis of location and prevalence of maxillary sinus septa. J Periodontal Implant Sci, 40: 56-60.

27. Lugmayr H, Krennmair G, Holzer H (1996) Morphologie und Inzidenz von Kieferhöhlensepten. Fortschr Röntgenstr, 165: 452-454.

28. Maestre-Ferrín L, Carrillo-Garcia C, Galán-Gil S, Peñarrocha-Diego M, Peñarrocha-Diago M (2011) Prevalence, location, an size of maxillary sinus septa: panoramic radiograph versus computed tomography scan. J Oral Maxillofac Surg, 69: 507-511.

29. Maestre-Ferrín L, Galán-Gil S, Rubio-Serrano M, Peñarrocha-Diago M, Peñarrocha-Oltra D (2010) Maxillary sinus septa: a systematic review. Med Oral Patol Oral Cir Bucal, 15: 383-386.

30. Meleo D, Mangione F, Corbi S, Pacifici L (2012) Management of Schneiderian membrane perforation during the maxillary sinus elevation procedure: a case report. Ann Stomatol, 3: 24-30.

31. Naitoh M, Suenaga Y, Kondo S, Gotoh K, Ariji E (2009) Assessment of maxillary sinus septa using cone-beam computed tomography: etiological consideration. Clin Implants Dent Rel Res, 11: 52-58.

32. Naitoh $M$, Suenaga $Y$, Gotoh $K$, Ito $M$, Kondo $S$, Ariji $E$ (2010) Observation of maxillary sinus septa and bony bridges using dry skulls between Hellman's dental age of IA and IIIC. Okijamas Folia Anat Jpn, 87: 41-47.

33. Neivert $H$ (1930) Surgical anatomy of the maxillary sinus. Laryngoscope, 40: 1-4.

34. Neugebauer J, Ritter L, Mischkowski RA, Dreiseidler T, Scherer P, Ketterle M, Rothamel D, Zöller JE (2010) Evaluation of maxillary sinus anatomy by cone-beam CT prior to sinus floor elevation. Int J Oral Maxillofac Implants, 2: 258-265.

35. Nunes LS, Bornstein MM, Sendi P, Buser D (2013) Anatomical characteristics and dimensions of edentulous sites in the posterior maxillae of patients referred for implant therapy. Int J Periodontics Restorative Dent, 33: 337-345.

36. Orhan K, Seker BK, Aksoy S, Bayindir H, Berberoğlu A, Seker E (2013) Cone beam CT evaluation of maxillary sinus septa prevalence, height, location and morphology in children and an adult population. Med Princ Pract, 22: 47-53.

37. Park YB, Jeon HS, Shim JS, Lee KW, Moon HS (2011) Analysis of the anatomy of the maxillary sinus septum using 3-dimensional computed tomography. J Oral Maxillofac Surg, 69: 1070-1078.

38. Pommer B, Ulm C, Lorenzoni M, Palmer R, Watzek G, Zechner W (2012) Prevalence, location and morphology of maxillary sinus septa: systematic review and meta-analysis. J Clin Periodontol, 39: 769-773.

39. Rosano G, Taschieri S, Gaudy JF, Lesmes D, Del Fabbor M (2010) Maxillary sinus septa: a cadaveric study. J Oral Maxillofac Surg, 68: 1360-1364.
40. Rossetti PH, Bonachela WC, Rossetti LM (2010) Relevant anatomic and biomechanical studies for implant possibilities on the atrophic maxilla: critical appraisal and literature review. J Prosthodont, 19: 449-457.

41. Rysz M, Bakoń L (2009) Maxillary sinus anatomy variation and nasal cavity width: structural computed tomography imaging. Folia Morphol, 68: 260-264.

42. Selcuk A, Ozcan KM, Akdogan O, Bilal N, Dere H (2008) Variations of maxillary sinus and accompanying anatomical and pathological structures. J Craniofac Surg, 19: 159-164.

43. Shen EC, Fu E, Chiu TJ, Chang V, Chiang CY, Tu HP (2011) Prevalence and location of maxillary sinus septa in the Taiwanese population and relationship to the absence of molars. Clin Oral Implants Res, 23: 741-745.

44. Shibli JA, Faveri M, Ferarri DS, Melo L, Vieir R (2007) Prevalence of maxillary sinus septa in 1024 subjects with edentulous upper jaws: a retrospective study. J Oral Implantol, 33: 293-296.

45. Toscano NJ, Holtzclaw D, Rosen PS (2010) The effect of piezoelectric use on open sinus lift perforation: a retrospective evaluation of 56 consecutively treated cases from private practises. J Periodontol, 81: 167-171.

46. Ulm CW, Solar P, Krennmair G, Matejka M, Watyek G (1995) Incidence and suggested surgical management of septa in sinus-lift procedures. Int J Oral Maxillofac Implants, 10: 462-465.

47. Undrewood AS (1909) Surgical considerations connected with the anatomy of the maxillary sinus. Br Med J, 15: 1.

48. Underwood AS (1910) As inquiry into the anatomy and pathology of the maxillary sinus. J Anat Physiol, [online].

49. Van den Bergh JP, ten Bruggenkate CM, Disch FJ, Tuinzing DB (2000) Anatomical aspects of sinus floor elevations. Clin Oral Implants Res, 11: 256-265.

50. Van Zyl AW, van Heerden WFP (2009) A retrospective analysis of maxillary sinus septa on reformatted computerised tomography scans. Clin Oral Implants Res, 20:1398-1401.

51. Velásquez-Plata D, Hovey LR, Peach CC, Alder ME (2002) Maxillary sinus septa: a 3-dimensional computerized tomoraphic scan analysis. Int J Oral Maxillofac Implants, 17: 854-860.

52. Vinter I, Krmpotic-Nemanic J, Hat J, Jalsovec D (1993) Does the alveoloar process of the maxilla always disappear after tooth loss? Laryngorhinootologie, 72: 605-607.

53. Wen SC, Chan HL, Wang HL (2013) Classification and management of antral septa for maxillary sinus augmentation. Int J Periodontics Restorative Dent, 33: 509-513.

54. Yang HM, Bae HK, Won SY, Hu KS, Song WC, Paik DJ, Kim HJ (2009) The buccofacial wall of maxillary sinus: an anatomical consideration for sinus augmentation. Clin Impl Dent Rel Res, 11: e2-e6.

55. Zijderveld SA, van den Bergh JP, Schulten EA, ten Bruggenkate CM (2008) Anatomical and surgical findings and complications in 100 consecutive maxillary sinus floor elevation procedures. J Oral Maxillofac Surg, 66: 1426-1438. 